\title{
Research Article Value and Challenges of Resilience Education Against Natural Disasters: Comparative Research between Japan and the USA
}

\author{
Noriko Hata*, David Allen**, Minoru Kikuchi*** \\ Tsuru University*, Texas A\&M International University**, Tokyo University of Agriculture and Technology*** \\ Accepted on May 20, 2019
}

\begin{abstract}
To clarify the value and challenges of resilience education, we discuss these based on the results of studies in floodaffected areas in Japan and the USA. We conducted qualitative research in Joso City, Japan after the 2015 flood including a review of a disaster prevention education program organized by the City Board of Education. In the USA we focused on the Texas coast and reviewed research literature, governmental and educational institution webpages and National Oceanic and Atmospheric Administration (NOAA) data on public educational events, all having a focus on rain-related disasters.

We conclude that resilience education could be enacted using knowledge and cognition gained through direct disaster experiences to make adaptations in preparation for future disasters. However, people tend to rely on the hope that they will not experience a disaster, and they tend to forget about disaster impacts with time. Therefore, it is necessary to provide opportunities to learn about the tenets of disaster prevention through the development of legal methods that continue to clarify the personal responsibilities of local residents. With legal clarification, resilience education that is specific to the city or region could be developed and implemented more effectively than the current approach to disaster resiliency.
\end{abstract}

Keywords: Community resilience, disaster risk reduction, education for sustainable development (ESD), natural disasters, resilience education

\section{Introduction}

Scientists' prediction that natural disasters will intensify due to climate change (Riebeek 2005) is becoming a reality. Seawater temperatures are rising due to global warming, which in turn increases the size of typhoons and the frequency and intensity of storms, floods, and landslides in areas of the West Pacific region such as Japan, Taiwan and the Philippines.

Sustainable Development Goals (SDGs) states "take urgent action to combat climate change and its impacts (SDG13)". Part of this action is to raise community resilience against natural disasters caused by climate change. From the viewpoint of environmental education (EE) and ESD, learning how to reduce disaster risks has become a new issue for sustainable development and it is required to raise community resilience.

Resilience education supports developing community resilience at all levels and in all settings. It includes not only formal disaster prevention education in schools (Fujioka 2016) and in training institution programs that offer certification for disaster prevention experts (Bousai-shi), but also non-formal education embedded in organized and planned activities in social educational facilities, i.e. Kominkans in Japan or Community Learning Centers (CLC) in other Asian countries. In addition, it includes informal community-based learning that does not occur in an organized and structured environment.

We next reviewed EE research related to resilience education. Dubois and Krasny (2016) state EE programs that reflected community resilience included neighborhood tours to connect people with each other and included using green space to foster place attachment and stewardship action. Williams et al. (2017) point out that children can learn about flooding and preparedness, and that intergenerational learning from children to parents can also occur, with children transferring the messages learned in school to home. Tidball et al. (2010) refer to a social mechanism 
associated with the act of memorializing those lost during the disaster or conflict as a memorialization mechanism. In our study, we also confirmed that it is important to visit the affected area, to learn between generations, and to document disasters. These learnings lead to action for preparedness against future disasters.

In this paper, we define community resilience as the capacity of regions and groups to minimize disaster risk and the ability of a community to recover after disaster. We focus on two case studies where community resilience developed in order to clarify the value and challenges of resilience education practiced in schools and communities. We conducted our research on resilience education drawing on literature and empirical research from local governments and from local residents' practices in areas where heavy rain disasters occurred frequently.

\section{Case Studies on Resilience Education Case Study 1 - Joso City, Ibaraki, Japan}

\section{(i) Overview}

On September 9, 2015, continuous rain bands followed one after another in East Japan stemming from a tropical cyclone-the remnants of Typhoon 18 that made landfall on the Chita Peninsula in Aichi. At the same time, Typhoon 17 was approaching the Kanto region. Flooding of rivers and landslides occurred in the Tohoku and Kanto regions due to the heavy rain. In Joso City, the inundation occurred along the levee of the Kinugawa River in the Wakamiyato District, causing a 200-meter section of the Kinugawa levee to collapse in the Misaka District. As a result, one third of the municipal area between the Kokaigawa River-running along the boundary of Tsukuba City and the Kinugawa River, which flows south through the center of the city-flooded, killing two people and injuring at least 40 more. As for residential damage, over 5,000 houses were affected, with 53 completely destroyed, 1581 half-destroyed, and 3,491 partially damaged.

It was revealed that delays in evacuation orders led to increased damage, and worse, that there were residents who did not voluntarily evacuate because their area was not affected in the previous flood of 1986 (Joso City 2016). Therefore, after the 2015 flood, Joso City took this issue seriously and emphasized disaster prevention education for citizens.

\section{(ii) Learning Program}

The Lifelong Learning Division of the Joso City Board of Education implemented a disaster prevention education program for elementary school 4th and 5th graders. After learning both the history of river flood control and local regional history from the staff, they visited riverbanks and wetlands to understand the terrain with the help of a drone. They also visited a shrine, castle ruins, and an old house, and they came to understand that these structures had been built in relatively high-altitude lands. In addition, they put stickers on the outer walls and fences of the flooded buildings to imagine the height of the flood waters. On the last day, to summarize what they had learned, they made dioramas that showed the differences in altitude in the city area and painted posters that illustrated their activities. Their posters are currently on display at the local museum.

\section{(iii) Research Methods}

We interviewed the staff of the Lifelong Learning Division on October 14, 2016, before the first disaster prevention session started. We asked about the situation at the time of the disaster and disaster prevention education after the disaster in Joso City. We also participated in the entire program, observed children participating, and administered a survey to the children and their parents upon completion of the course.

The program was held four times, once every two months from November 2016 to May 2017. Eleven children participated in the final day, and seven children participated all four times. When asked if they participated voluntarily in the program, ten children answered positively. We obtained various reasons for participation: "I wanted to operate the drone"; "I was interested in the history of Joso City"; and "I wanted to know the topography of Joso City." Moreover, we asked their parents about their experiences during the flood. Of the nine people who answered, one person's house had been half-buried, one flooded underneath the floor, and the remaining seven people responded 
that their homes had not been affected. When asked about the content of the course and what they learned about preparing for disasters, common responses were as follows: (1) understanding the history of the river and flood control; (2) recognizing that the shrines and the castle ruins were located on river terraces and had been free from the flood damage; (3) operating the drone and learning about the river terrain of the basin; (4) learning to understand the terrain of the area by making the diorama; and (5) putting the water-level stickers on the outer walls and fences of the flooded buildings raising their awareness of the height of the flood waters. They answered that these learning activities were "learning to prepare for disaster."

Next, we analyzed qualitative data from the survey. We examined the sentences that the children and their parents wrote to clarify the value of their disaster prevention education, segmented them, and then classified them into categories.

\section{(iv) Results}

As a result, we discovered the following five categories (Table 1). First, as shown in the category "Knowing the circumstances of the damage", the learners perceived the severity of the flood damage by putting the water-level stickers on the outer walls and fences of the flooded buildings. Second, the categories "Understanding the terrain", "Learning the wisdom of the ancestor", and "Knowing the risk of disasters" showed that the learners recognized that their residential areas may be at risk of disasters by understanding the terrain and history of the area. Third, the category "Learning that leads to actions" shows that the learners understood evacuation routes if a flood occurred again. Finally, the learners understood their educational activities as learning to prepare for future disasters.

Table 1 The learning of the children and their parents

\begin{tabular}{ll} 
Categories & Samples of their descriptions \\
\hline $\begin{array}{l}\text { Knowing the circumstances } \\
\text { of the damage }\end{array}$ & $\begin{array}{l}\text { Knowing how much the buildings were flooded by sticking seals, which showed the } \\
\text { water level, and I realized the fear of flooding. (6th graders) }\end{array}$ \\
\hline $\begin{array}{l}\text { Learning that leads to } \\
\text { actions }\end{array}$ & $\begin{array}{l}\text { By examining the topography, I understood where to evacuate when the flood } \\
\text { occurred. (5th graders) }\end{array}$ \\
\hline $\begin{array}{l}\text { Understanding the terrain } \\
\text { In making diorama, I thought that skipping the drone and examining the topography } \\
\text { was useful. (5th graders) }\end{array}$ \\
$\begin{array}{ll}\text { Learning the wisdom of } \\
\text { the ancestor }\end{array}$ \\
$\begin{array}{l}\text { I understood that most of castle ruins, shrines and temples were safe from floods } \\
\text { because they are located in highlands. (parent) } \\
\text { disasters }\end{array}$ & $\begin{array}{l}\text { Learning the terrain of the area, I knew our residential areas were never safe. } \\
\text { (parent) }\end{array}$ \\
\hline
\end{tabular}

\section{Case Study 2 - Gulf of Mexico coast, Texas, USA}

\section{(i) Overview}

Between 1851 and 2008, Texas, USA experienced 120 tropical cyclone events that reached tropical storm $(n=56)$ or hurricane $(n=64)$ strength for an average of 0.8 storms of these levels per year. Of note is the Galveston Hurricane of 1900. The city of Galveston, Texas is positioned on the coast about 60 miles southeast of Houston, Texas. In 1900, the population was approximately 30,000. When the hurricane warning of the day was issued on August 7 th, about two-thirds of the population evacuated. Of the 10,000 that remained, about 8,000 were killed when the hurricane made landfall. A decision was made to raise the elevation of Galveston Island and construct a seventeen-foot tall seawall that extended three miles along its coast. Eight more hurricanes have struck Galveston since and only one had over 100 associated deaths (Roth 2010).

More recently, Hurricane Harvey approached the city of Galveston on August 25, 2017, and made landfall in the state of Louisiana, just east of Houston. In addition to strong winds and weak tornadoes, slow-moving Harvey 
released 60.58 inches (1.54 meters) of rain, setting a new USA tropical cyclone rain record. The rain bands dropped precipitation at rates up to 6.8 inches per hour producing catastrophic floods in Harris and Galveston Counties. Additionally, a 6 to 10 foot (1.8 - 3.0 meter) storm surge inundated coastal areas. Hurricane Harvey resulted in 68 direct and 35 indirect deaths. Damage estimates were put at $\$ 125$ billion, making Hurricane Harvey the second most costliest (adjusted for inflation) disaster resulting from a tropical cyclone (Blake and Zelinsky 2018).

\section{(ii) Learning Program}

Based on the literature review, resilience education in the USA primarily uses knowledge gained during past disasters to make adaptations to prepare for future disasters. There seem to be few documents on preparedness and the education of youth and families (National Strategy for Youth Preparedness Education by the United States Federal Emergency Management Agency and American Red Cross; Hurricane Preparedness \& Resource Guide for Individuals and Families by Magellan Health Services).

An adaptation example of resilience is the previously mentioned response to the Galveston hurricane of 1900. As Galveston grew, seawall additions expanded this wall to its current length of 10 miles (Whalin et al. 2014). Eighty years of technological advancements, such as meteorological radars and satellites, now provide data to predict the courses of hurricanes, helping to prevent the severity of disasters. These predictions allow for earlier warnings that provide information that could be regarded as a form of short-term resilience education to help the public make informed decisions about preparations for upcoming potential disasters. Since the estimated 8,000 dead in 1900 Galveston, the Texas coast data show the positive results from adaptive resilience strategies (construction of the seawall) and short-term resilience education (improved hurricane warning systems) pertaining to hurricanes. With 46 hurricane-level storms making landfall in Texas since 1900, the mean $(\mu=27)$ and median $(M d n=4)$ number of deaths have been greatly reduced. According to Roth (2010), eight of these storms had no associated deaths.

The US Department of Homeland Security (DHS) and the United States Federal Emergency Management Agency (FEMA) "Ready" Campaign has been in place since the September 11, 2001 terrorist attack on the World Trade Center in New York City. A 2014 FEMA publication provided the most comprehensive analysis of the level of preparedness in the USA since this the start of this campaign. The FEMA study is nationally representative of the adult population $(n=5008)$ and provides a high-level overview of disaster preparedness. Table 2 provides a partial summary of the national response the FEMA survey.

Table 2 USA National Response to DHS/FEMA "Ready" Campaign Survey

\begin{tabular}{lcccc}
\hline \multicolumn{1}{c}{ Focus area } & $2007(\%)$ & $2009(\%)$ & $2011(\%)$ & $2012(\%)$ \\
\hline Informed & & & & \\
$\quad$ Know about local hazards & 49 & 51 & 32 & 46 \\
Preparedness trained in past two years & 37 & 41 & 43 & 46 \\
Have Emergency Plan & 37 & 41 & 42 & 39 \\
Have Emergency Kit & &
\end{tabular}

Note: Source is FEMA (2014).

Chris Maier of the USA Government's National Oceanic and Atmospheric Administration (NOAA) provides statistics for educational events that include rain-related disaster topics for the coastal regions of Texas, Louisiana, Mississippi and Alabama. These types of activities include staffed booths, formal education (classes or course work), office tours, open houses, presentations/talks, safety awareness campaigns, school visits by NOAA staff to talk to school children, site visits, and SKYWARN trainings. Data from these events are presented in Table 3. The lower totals attendance for 2012-13 are attributed to under reporting of attendance and the spikes for 2015-16 are due to activities being present at a heavily attended Houston Airshow. The increased attendance for presentations in 2017 is attributed to the rapid succession of major hurricanes Harvey, Irma, and Maria from mid-August through September of 2017. 
Table 3 NOAA Public Educational Events Partial Gulf Coast Region 2012-2017

\begin{tabular}{|c|c|c|c|c|c|c|c|c|}
\hline \multirow[b]{2}{*}{ Year } & \multicolumn{2}{|c|}{ Formal Education } & \multicolumn{2}{|c|}{ Presentations } & \multicolumn{2}{|c|}{ School Visits } & \multicolumn{2}{|c|}{ Totals } \\
\hline & Events & Attend & Events & Attend & Events & Attend & Events & Attend \\
\hline 2012 & 10 & 63 & 359 & 32686 & 25 & 1597 & 688 & 52971 \\
\hline 2013 & 12 & 118 & 433 & 34273 & 14 & 849 & 808 & 103869 \\
\hline 2014 & 6 & 120 & 309 & 21421 & 20 & 4515 & 578 & 137992 \\
\hline 2015 & 4 & 1514 & 265 & 18832 & 72 & 11870 & 673 & 203134 \\
\hline 2016 & 7 & 177 & 331 & 21816 & 62 & 11713 & 742 & 201966 \\
\hline 2017 & 6 & 65 & 301 & 73196 & 36 & 4606 & 705 & 111898 \\
\hline Total & 45 & 3557 & 1998 & 202224 & 232 & 35150 & 4194 & 813330 \\
\hline
\end{tabular}

Note: Source is NOAA (C, Maier pers. Comm.)

\section{(iii) Research Methods}

The primary source for the Texas, USA tropical cyclone data is the NOAA database. Additionally, a literature review was conducted to identify research studies that included an educational component of disaster resiliency. Finally, web pages of several school districts in affected coastal communities were reviewed to see if they incorporate disaster preparedness into their general curriculum. The web page of the Texas Education Agency (TEA), the statelevel agency that controls public education in Texas, was also reviewed.

The TEA web page provided information about logistical matters but there is no information regarding disaster preparedness education. The review of school web pages also found no mention of disaster preparedness education. Extensive literature exists for disaster resiliency but it mostly involves infrastructure and rebuilding, with no educational component. The few results that did incorporate education came from governmental organizations and focused on disaster preparedness: keep informed, have a home emergency plan, build an emergency kit, and get involved. These four areas are the primary focus of the US Department of Homeland Security (DHS) and the United States Federal Emergency Management Agency (FEMA) "Ready" Campaign referenced with Table 2 above.

\section{(iv) Results}

There are challenges for resilience education in the USA. Based on responses to the DHS/FEMA survey from 2011 (FEMA 2014), 26\% of the non-prepared participants indicated the perceived expense and 24\% indicated a lack of understanding of how to prepare as the primary reasons for their lack of preparedness. Redlener (2006) also asserts that citizens of the USA are unsure about how to prepare, instead expecting the government to make necessary preparations for disasters and provide the appropriate response when needed. He contends that USA citizens mostly rely on the hope that they will not experience a disaster. This hope persists even with major hurricanes (category 3 or greater on the Saffir-Simpson scale) (NOAA 2014) striking the Texas coast on average once every 6.5 years. Additionally, USA citizens tend to forget about disaster impacts with time passing. This notion is supported by anecdotal attendance records at NOAA educational events, which see a rise in attendance immediately after a disaster, returning to pre-disaster levels soon after (D. Reilly pers. comm.). Combine a hopeful outlook, short term memory, and deference to the government for action and the result is a difficult path for resilience education in the USA.

\section{Perspectives for a Resilient Community's Future}

To raise community resilience, it is necessary for residents to fully recognize "Unsafe Conditions" (Wisner et al. 2004, p.55)-that is, they should recognize that their residential areas are not safe from disasters. Regarding the case study of Joso City, the learners learnt about the extent of the flood damage and recognized through learning activities that their residential areas may be at risk of future disasters. Moreover, the learners came to understand evacuation routes that they could use if needed. Therefore, we conclude that resilience education could be designed by using knowledge and cognition gained through direct disaster experiences to make adaptations in preparation for future disasters.

On the other hand, in the USA case study, we found that US citizens tend to rely on the hope that they will not 
experience a disaster, and they tend to forget about the impact of disasters with time. This approach also applied to the Japanese case study, as there were residents who did not voluntarily evacuate in Joso City, even though it had experienced flood damage eight times over the past 80 years. But in Joso City, an informal education program was designed to educate citizens. After the flood in 2015, a citizen group organized study meetings at the city hall to share experiences from this disaster, and conducted study tours where affected people talk about their experiences with flooding. In building community resilience, it is crucial that residents actively pursue informal learning opportunities.

Some differences exist between both countries. In Japan, there have been voluntary disaster prevention organizations that have helped prepare for large fires since the Edo era (about 300 years ago). Even now, residents' associations carry out disaster resilience drills and stockpile supplies. However, as membership in these associations decreases with urbanization, legal clarification of residents' responsibilities has become very important.

The disaster law (Saigaitaisakukihonhou) was revised two years after the Great East Japan Earthquake that occurred in 2011. The legislation is reviewed each time a major disaster strikes Japan. According to these laws, residents must prepare reserves of food, drinking water, and other essential supplies. They also must make efforts to contribute to disaster resilience through participation in drills and other voluntary activities and by passing on their ancestors' experiences with past disasters to the next generation. In this way, legislation clarifies the responsibilities of local residents to be self-reliant in the face of a disaster (Nakayama 2015).

However, issues arise when the population is not prepared for disasters and is too reliant on governmental support for assistance. When relying heavily on government assistance, the following perspectives should be considered. First, Marcario (2017) describes a difficult situation for both military personnel and disaster victims when responders must bypass those in need of help in order to reach victims in greater need. Second, Marcario also discusses how two major hurricanes (Harvey and Irma) affected the USA just two weeks apart, stretching the available governmental forces very thinly. Five days after his article went to press, a third major hurricane (Maria) devastated the US territory of Puerto Rico. A population educated in disaster preparedness for resilience will help to protect themselves and their property, while at the same time reduce the strain on governmental resources.

In the USA, FEMA provides youth preparedness school curricula for all levels of public education and NOAA provides disaster preparedness training, but a lack of preparedness for rain-related disasters is still evident in the US population. Redlener (2006) asserts that citizens themselves are likely the long-term first responders when experiencing a major disaster. This likelihood results from traditional responders either falling victim themselves, or being too few for the magnitude of the event. Resources are available to the US public to educate themselves for disaster resilience; however, the motivation must be present to proactively use these resources for educating the public to ensure a resilient future.

Therefore, it is necessary to provide opportunities to learn the tenets of disaster prevention through the development of legislation that continues to clarify the personal responsibilities of individual residents in a disaster. With such clarification, resilience education that is specific to the city or region could be developed and implemented more effectively than the current approach to building disaster resiliency.

\section{References}

Blake, E.S., and Zelinsky, D.A. 2018. Hurricane Harvey: 17 August - 1 September 2017 (Report No. AL092017). Florida: National Hurricane Center.

Dubois, B., and Krasny, E.M. 2016. Educating with Resilience in Mind: Addressing Climate Change in Post-Sandy New York City. The Journal of Environmental Education. 47(4):255-270.

Federal Emergency Management Agency. 2014. Preparedness in America: Research Insights to Increase Individual, Organizational, and Community Action.

https://www.fema.gov/media-library-data/1409000888026-1e8abc820153a6c8cde24ce42c16e857/20140825 Preparedness_in_America_August_2014_Update_508.pdf, accessed 28 June 2018.

Fujioka, T. 2016. Disaster Prevention Education in the Japanese School Curricula in Recent Years: Current Status and Future Challenges. In Disaster Resilience of Education Systems: Experiences from Japan, edited by Shiwaku, K., Sakurai, A., and Shaw, R., 39-52. Springer Link, https://link.springer.com/chapter/10.1007/978-4-431-55982-5_4, 
accessed 19 January 2019.

Joso City. 2016. Heisei 27 nen Joso-shi Kinugawa Suigai Taiou ni Kansuru Kensyou Houkokusyo: Wagakototoshite Saigai ni Sonaerutameni.

http://www.city.joso.lg.jp/ikkrwebBrowse/material/files/group/6/kensyou_houkokusyo.pdf, accessed 11 July 2018. (in Japanese).

Marcario, J.C. 2017. Rescue, Relief, Recovery: Back-to-Back Historic Hurricanes Bring Broad Multi-Agency Response. Sea Power. 60(8):32-33.

Nakayama, H. 2015. Juminsyukengatagennsai no machidukuri: Hanshin-awaji daishinsai ni manabi Nankaitorafujishin ni sonaeru. Kyoto: Mineruva Shobou. (in Japanese).

National Oceanic and Atmospheric Administration. 2014. What is a Super-Typhoon? What is a Major Hurricane? What is an Intense Hurricane? http:/www.aom 1.noaa.gov/hrd/tcfaq/A3.html, accessed 28 June 2018.

Redlener, I. 2006. Americans at Risk: Why We Are Not Prepared for Megadisasters and What We Can Do Now. New York: Alfred A. Knopf.

Riebeek, H. 2005. The Rising Cost of Natural Hazards. NASA website: http://Earthobservatory.nasa.gov, accessed 28 June 2018.

Roth, D. 2010. Texas Hurricane History. Camp Springs. Maryland: National Weather Service.

Tidball, G.K., Krasny, E.M., Svendsen, E., Campbell, L., and Helphand, K. 2010. Stewardship, Learning, and Memory in Disaster Resilience. Environmental Education Research. 16(5-6):591-601.

Whalin, R.W., Richardson, T.W., Das, H.S., Hendon, D.L. 2014. A Coastal/Ocean Engineering Graduate Project: Evaluation of Hurricane Protection Concept. Proceedings of the American Society for Engineering Education. 121, 24.25.1-24.25.15.

Williams, S., McEwen, L.J., and Quinn, N. 2017. As the Climate Changes: Intergenerational Action-Based Learning in Relation to Flood Education. The Journal of Environmental Education. 48(3):154-171.

Wisner, B., Blaikie, P., Cannon, T., and Davis, I. 2004. At Risk: Natural Hazards, People's Vulnerability and Disasters (2nd ed.). New York: Routledge. 